\title{
Fieldwork as a Participatory Research Activity: The Mayangna Linguistic Teams
}

\author{
Elena Benedicto, Modesta Dolores, Melba McLean
}

Purdue University, URACCAN, CIDCA

\section{Introduction}

In dealing with endangered languages, focus has been shifting from the languages themselves and their scientific documentation to the communities that speak such languages. This paper is an attempt to examine how linguistic, scientific research can be conducted in a way that actively involves and empowers the target community-an approach which falls under the umbrella of what may be known as participatory research.

In this paper, we will address the particular goals and theoretical bases of a participatory-research-based approach to linguistic research $(\S 1$ and $\S 2)$, we will present some of the projects that have been or are presently being conducted in Nicaragua $(\S 3)$, and we will evaluate the preliminary results of those projects ( $\$ 4$ and $\S 5$ ).

\section{The Goals of the Approach}

When considering the variable of the community, doing linguistic research on an endangered language presents a series of issues having to do with power, control, and agentivity. The last of these issues - that of agentivity-is perhaps the most obvious one. The agent of the research is the linguist, usually an outsider to the community. The members of the community have little or no agentive behavior, but rather are simply "informants." Issues of control have to do, among other things, with questions like what is being done with the elicited materials, who has access to them, and how will they be used in the short and the long term. The first question is perhaps the most complex, and one which we will not even attempt to address as it deserves. For the purposes of this paper, let us suggest just one venue of thought: as one informant once put it, "If they don't explain anything to me, if they just use me as an informant [i.e., if there is no transfer of knowledge], I don't gain anything, I remain the same, what's the gain?" Knowledge allows people to make their own informed decisions about issues that affect them, such as 
language policies. In other words, knowledge is power; without it, the power to decide remains with others.

The general goals of the approach to linguistic research that we are suggesting here are, first, to empower the community by jointly (re)creating knowledge (thus, addressing issues of imbalance of power) and, second, to emphasize the documentation and preservation process as one for the benefit of the language community as well as of the scientific community (along the lines of suggestions such as those of Deloria (1969), Hale et al. (1992), Bach (1995)). More concretely, the specific goals are: (i) to involve the community more successfully in the linguistic activities having to do with their language; (ii) to establish a more equal-to-equal relationship between the community members and the linguist; and (iii) to transfer the linguistic "technology" back to the community, i.e., to foster an environment for native linguists to emerge.

\section{The Ideological/Theoretical Bases}

The goals established in the previous section are in line with what has been called Participatory Action Research (PAR), an approach developed in the (social) sciences in the context of environments of social imbalance (see Christie et al. (2000)). The approach taken by PAR intends, specifically, to reduce the power imbalance between "scientist" and "object of study"; to transform the relation "subject-object" into a "subject-subject," that is, to involve local members as agents in the process of knowledge generation; and to create knowledge that is useful, that can effect change in the lives of the original "objects." Research, then, is viewed as the articulation of a co-learning process that takes place at all levels (crucially involving what are now two "subjects"), and the subsequent change that it effects.

Christie et al. (2000) propose a broad methodological process, which includes three basic steps. First, research priorities need to be set and key problems and issues identified. Second, the causes underlying those problems and issues need to be analyzed. Finally, action needs to be taken to find both short-term and longterm solutions for the identified problems. We will use this approach with respect to the linguistic situation the Mayangna face.

In the context of the indigenous communities of Nicaragua and, more specifically, in its Northern Atlantic Region (RAAN), the Mayangna find themselves in a situation that, while not unique in its broad features, did present some idiosyncracies with respect to other indigenous or local communities in the area. The Mayangna are a relatively small indigenous community inhabiting the North Central area of Nicaragua, part of what is known as the RAAN. The language is spoken by a little over 10,000 speakers at varying degrees of endangerment (though it is strong and healthy for a good core of speakers). It is a member of the Misumalpan family, an isolate group (see Craig \& Hale (1992)), and three dialectal variants are presently known: Tawahka in Honduras, and Tuahka and Panamahka in Nicaragua (see Benedicto \& Hale (2001)). A bilingual 


\section{Fieldwork as a Participatory Research Activity}

program for primary school was begun in the early 1980's in Nicaragua and thus began a structural need for decision making in the linguistic realm. The projects described in $\$ 3$ began in the late 1990's, after more than a decade of bilingual programs, thus inheriting a certain structural set up. All of these projects share a basic set of conditions, as established by Christie et al. (2000) (see above). First, the research priority was to enlarge the body of knowledge about the language as needed for primary school materials such as dictionaries and textbooks, but also for the particular linguistic contents to be included in the curriculum. Additionally, the teachers' rising level of training required new materials, such as grammars. Finally, the revision of school curriculum required culturally relevant materials such as collections of oral histories, stories, and traditions. The key problem identified for this project was the lack of local language experts. The most immediate cause for this situation was the absence of appropriate, locally available training mechanisms. The projects described below were born, as shortand long-term solutions to this situation, within a more general framework of creating a model of education relevant for the Atlantic Coast of Nicaragua.

\section{The Projects}

These projects are carried out in Nicaragua in conjunction with a series of institutions that work regularly in the area of the Atlantic Coast of Nicaragua (RAAN and RAAS), all of them committed to the development of bilingual intercultural education. These institutions are URACCAN (the University of the Atlantic Coast of Nicaragua), CIDCA (the Center for Research of the Atlantic Coast of Nicaragua), several NGOs involved in bilingual and intercultural education (the Italian Terra Nuova, Danish Ibis, Finnish Kepa, and Austrian OED), and last but not least the Program for Bilingual Intercultural Education, PEBI, a division of the Ministry of Education. In initiating and developing a program of linguistic research, the role of Ken Hale and the group Linguists for Nicaragua was absolutely instrumental beginning in the mid to late 1980 's.

\subsection{The Tuahka Project: TUYUWAYABA (1995-present)}

Tuahka is the minority dialectal variant of Mayangna spoken by some 1,000 people around the area of Wasakin, near Rosita, RAAN (see Benedicto \& Hale (2001) for an overview of its morphological properties). It is more endangered than its counterpart, Panamahka. In 1995, following a request by some of the members of the community, a group was formed to carry out an overview of the dialectal variant. This initial group grew into the team later called TUYUWAYABA, Tuahka Yuln Walwi Yakwi Balna 'Group for the Research of the Tuahka Language'.

\subsubsection{Initial Problem(s)}

The situation that prompted the members of the Tuahka community to organize into this group can be summarized as a lack of representation of this linguistic 
minority in the structure of the educational system. All of the materials and textbooks in PEBI were written in Panamahka, the majority variant, and there was no Tuahka member among the technical staff of PEBI (the bilingual section of the Ministry of Education).

\subsubsection{Goals}

The goals of the team were (i) to document the Tuahka linguistic variant, (ii) to train a group of technical staff in the linguistic "trade" (e.g., collection and handling of data), (iii) to pilot-produce some school materials in Tuahka, and (iv) to collect a set of culturally relevant materials (oral history, folktales, oral traditions, etc.).

\subsubsection{Participants}

The group is formed by eight members: three women and five men from the community of Wasakin. A member of the team has been, on and off, included in the PEBI technical staff. Unfortunately, however, the Ministry of Education has not yet officially recognized that person as the Tuahka representative.

\subsubsection{Accomplishments}

The efforts of the team have coalesced into three types of products. First, they produced a preschool Tuahka textbook, which was published and is currently in use; other textbooks $\left(1^{\text {st }}\right.$ and $2^{\text {nd }}$ grade) were also prepared but were not published (though they will be considered for the new curricular plan). Second, supporting cultural material has been collected: twenty-one folk stories (of which ten are currently being published), as well as a collection of oral history and traditions. Finally, all of the lexical material contained in the stories and folktales has been prepared as lexical entries for a dictionary. Originally, a small vocabulary was produced in 1996 (Breve Vocabulario Twahka); an expanded version is presently being included into the Mayangna Dictionary (see $\$ 3.3$ ).

\subsubsection{Funding}

Funding for TUYUWAYABA has been provided by The Irish Student Group, Linguists for Nicaragua, the Foundation for Endangered Languages, and URACCAN University in Nicaragua.

\subsubsection{Evaluation}

As a result of these actions, two types of outcomes can be identified. One concerns what could be dubbed as "positive results" and another one as "new issues/problems identified."

In the first category we can list the fact that the dialectal variant has been studied and the community now has a "linguistic evaluation" of itself (which was the original concern of the community). More importantly, the community's "linguistic right to existence," so to speak, has been acknowledged. The PEBI 
section now has a permanent Tuahka staff member (though not recognized as such by MED). Furthermore, a considerable amount of culturally relevant material has been collected (though not completely published). Finally, the group is beginning to set up new goals and organize activities on their own, without the participation of the outsider linguist.

In the second category of outcomes we can include the realization of the role of old, well-established dynamics. On the one side, internal divisions within the small community, reproduced in the group, can paralyze its smooth functioning. On the other side, we could find an external factor: the role of the community atlarge and the local politics at play. Old rivalries between the majority group Panamahka and the minority Tuahka have found their way into the linguistic debate, though it seems that, at least up to now, they are being treated in the climate of an open and civilized conversation.

\subsection{The Women's Project (1997-2000)}

\subsubsection{Initial Problem}

There were no women working as technical staff in PEBI. Generally speaking, very few women were trained to carry out a position of responsibility, though a number of them were teachers or teachers-in-training, and at least one was a university student.

\subsubsection{Goals}

The initial goal of the project was to train women in linguistic techniques so that they could eventually opt at positions as technical staff members at PEBI in matters related to language. More specifically, they were to be trained in how to collect linguistic data (taping, transcribing, etc.); how to prepare a text for publication (using punctuation, standard orthography, etc.); and how to prepare a lexical item as a dictionary entry.

The broader goals of the project were to develop leadership and organizational skills in the members of the team and to prepare women to successfully compete for well-paying and well-regarded jobs.

\subsubsection{Participants}

A total of five women participated in the program. One of them worked as the local coordinator of the team. She was a speaker of Panamahka and one of the few Mayangnas - and the only woman-with a University degree. Two other women in the program were also speakers of Panamahka (one in Awastingni/Bilwi, one in Sakalwas), and the remaining two participants were speakers of Tuahka (in Wasakin).

\subsubsection{Accomplishments}

The team has produced two collections of women's life stories, one of them already published (Benedicto et al. 1999). Two illustrated dictionaries for 
preschoolers and $1^{\text {st }}$ and $2^{\text {nd }}$ graders have also been produced and are now awaiting publication. These are bi-dialectal dictionaries (in Panamahka and Tuahka), the first of their kind in the Nicaraguan context. Finally, lexical data in the women's stories were prepared as lexical entries for the Mayangna Dictionary (see $\$ 3.3$ ).

\subsubsection{Funding}

Funding for this project came, originally, through the Seminari d'Estudis de la Dona ('Women's Studies Seminary') (SIED) via a cooperation program of the Paeria de Lleida (the City Hall of Lleida) in Catalunya, Spain. Further funding was provided by the Endangered Languages Foundation at Yale University and by the Linguistics Program at Purdue University.

\subsubsection{Evaluation}

As with the previous project, two sorts of outcomes can be identified-one that acknowledges the positive effects of the project, and one that discovers new problems or issues.

On the positive side, we can cite the fact that the women in the group now know and use their linguistic skills fully. One of the women is now working as a technical staff member in the PEBI and another was named director of the Bilwi office of CIDCA. A third participant has organized a new independent research group and has initiated several projects.

The new problems and issues that were identified concern, once again, questions of the internal politics of the community, more concretely, issues of power and the role of women within the community. In fact, this is not an unexpected problem but a common outcome of any kind of activity that questions the roles traditionally assigned to women. As an internal process within the community, it needs to follow its course of discussion. With respect to the issue of building self-confidence, the project was quite successful in its internal dynamics. However, once the women were integrated into mixed, male dominated groups, their participation dropped dramatically. Finally, the questions arose of what to do with the collected texts, who has "ownership" of them, who has control over them, who has access to them and under which circumstances, etc. The women who told their stories agreed that they be published for use in the bilingual system. Now, some groups have requested to have translations made in other languages, but some of the women may not be alive anymore for consent. These questions only add to the growing need for establishing guidelines that recognize both individual and community rights to the linguistic materials collected during research. 


\subsection{The Linguist Team Project (2000-present)}

\subsubsection{Initial Situation}

As already pointed out at the end of $\S 2$, one of the key problems identified was the lack of local, indigenous linguists. As a result, the community was not selfsufficient and had to rely on outsiders for linguistic matters ranging from setting consistent orthographic standards, to preparing and revising textbooks for the bilingual program, to editing and publishing texts.

\subsubsection{Goals}

In preparing this project, three goals were established. The first, general, longterm goal was to get the language community in a position to be self-sufficient in linguistic issues. In order to achieve this, the second, concrete, goal was to create and train an indigenous team of future linguists. The duties of such a team would be to assist the bilingual program (PEBI) in linguistic matters, to assist other institutions in the publication of materials in Mayangna (e.g., with respect to orthographic standards), and to develop deeper knowledge of their own language (that is, to become involved in linguistic research). Finally, the third, specific goal was to obtain reference materials on Mayangna relevant for the community: bidialectal monolingual dictionaries (with definitions in Mayangna and lexical entries in the two dialects), teaching grammars, etc.

\subsubsection{Participants}

A total of nine people are participating in this project-six women and three men. Six of them are teachers in the bilingual program, PEBI. The regional coordinator is a speaker of Panamahka; she is also the director of the CIDCA office in Bilwi. Five of them are speakers of Panamahka and three are speakers of Tuahka. Except for the regional coordinator, who already has a University degree, all of them are students in the Bachelor's Degree program for Bilingual Intercultural Education conducted by URACCAN University (see below, \$3.4).

This project has fed from the experience and participation in the two previous projects. Five of the six women in this project participated in the Women's Project and, thus, had quite a bit of experience in these matters. Three of them are Tuahka speakers and had also participated in the Tuahka Project, so their experience was double.

\subsubsection{Activities}

Work has concentrated on creating and revising lexical entries for a bi-dialectal (Tuahka and Panamahka), monolingual (with definitions in Mayangna) dictionary. The dictionary is currently in the final revision stage. The next project is a grammar for teachers in the bilingual program, written in Mayangna.

The members of the team have worked both individually and as a group. They meet monthly for self-evaluation and feedback and they have two training 
workshops a year, where the previous phase is evaluated and goals for the next one are set.

\subsubsection{Funding}

The main sponsor of the project is CIDCA, with funds from AID/MED and substantial support from SAHWANG (an organization formed by the NGO's Terra Nuova, Ibis, and Kepa). The Linguistics Program at Purdue University has also provided support sporadically.

\subsubsection{Evaluation}

On the positive side, the level of training has indeed risen and, thus, the level of linguistic sophistication, a substantial step towards the initial goal of creating an indigenous local team of linguists. In the same way, the level of awareness and ability to identify problems has grown, as well as the level of personal commitment to the project among the participants (i.e., the ability to see the project as one's own, and not as one more outsider's project). Finally, the first volume of the dictionary is about to come out and the second volume will soon follow.

The problems and issues that were identified are not new. In fact they had already been talked about in Christie et al. (2000). Though the level of organizational and leadership skills augmented over the course of the project, it became painfully obvious that organizational training was far more important than originally thought; it can never be stressed enough how this point can affect the outcome of a project. Furthermore, faction and gender power struggles internal to the community at large were reproduced inside the group, though one must acknowledge that as the group's awareness and sense of identity grew, those factors decreased. At another level, one could mention the difficulties posed by old, deeply rooted pre-conceptions, in particular, the idea that "the foreigner knows best and is the one to decide on issues," and also the difficulty recognizing that the community is itself a source of knowledge and that they themselves can create knowledge. Finally, certain economic expectations and dependency on outsiders were created that led some to consider the project more as source of easy money than as a source of empowerment and intellectual growth. This was by no means a product of this particular project, but rather a reflection of the general climate and attitudes in the region towards external cooperation.

All of these issues do nothing else than underscore the fact that this is an ongoing process of co-learning and that, through the identification of new "problems," better solutions can be found.

\subsection{Other Projects (1996, 1998-present)}

The picture sketched here would not be complete without mentioning the role that the Bachelor's Degree in Bilingual Intercultural Education has had and has in providing crucial logistic, ideological, and intellectual support for the task of 


\section{Fieldwork as a Participatory Research Activity}

building a local scientific community. The degree program offered by URACCAN (the University of the Atlantic Region and Caribbean Coast of Nicaragua) has provided the pool of students to participate in these projects and has fostered the intellectual and participatory climate without which they would not have flourished.

Additionally, the Mayangna Girls and Women's Project (http://icdweb.cc.purdue.edu/ benedict/sumu), an independent project administered by CIDCA-UCA, has worked towards augmenting the pool of women feeding the university, by increasing their participation in secondary education.

In sum, as already mentioned at the beginning of $\$ 3$, the projects referred to in this paper have benefited greatly from a general climate of cooperation and mutual knowledge creation among different institutions and organizations.

\section{General Evaluation}

In evaluating these projects as steps or modules within a single multi-focal process, itself part of a larger task of creating a multilingual intercultural model of education relevant for the Atlantic Coast of Nicaragua, some recurrent patterns emerge. Let us consider them in turn.

Though the specific and concrete goals were achieved (the dictionary is in the process of being published, culturally relevant material has been or is being published, some members of the community are better trained in linguistics and are continuing the process), it became obvious that attention needed to be shifted to, or at least needed to include, the process itself. The generation of a product (such as a dictionary) is merely an indicator, but not the only one. In evaluating the process, three variables emerge, which, of course, should not be considered an exhaustive list.

First, more detailed organization of the work is needed, especially under the current circumstances, where members of the team are not in permanent contact. Both in the case of the Women's Project and of the Linguists Team, the members were scattered throughout a number of distant and often difficult to reach communities. Local members met once a month and the outsider linguist met with them twice a year, though telephone and e-mail contact was maintained when and where possible. ${ }^{1}$ Though a plan of work was designed at the beginning of a sixmonth period and evaluated at every monthly meeting, more detail in the planning, in the actions to be taken, and in the treatment of contingencies would have gone a long way towards improving the co-learning process. A second lesson learned was that it is equally important to assign individual responsibilities as it is to assign group responsibilities. The former increase the participants' sense of self-worth and of accomplishment, the latter emphasize the aspect of being part

\footnotetext{
' Local (URACCAN, CIDCA and Terra Nuova) offices in Managua acted as points of contact for telephone and e-mail. Lately, too, Bilwi has obtained e-mail access by satellite. The towns of Rosita and Bonanza (closer to some of the communities) had telephone lines, however unreliable.
} 
of a larger more far-reaching and long-term project. Though this is in principle a good assessment of the situation, it must be said that it interacts with variables as of yet poorly understood. More concretely, increasing individual responsibilities greatly improved the dynamics of the group in the case of the TUYUWAYABA project, while it did nothing for the Linguists Team. In the case of the Women's Project, individual and group responsibilities worked in near-perfect combination. The third observation, which interacts with this last one, has to do with introducing more specific and process-related self-evaluation mechanisms, especially some that would push the members to look for causes and possible solutions and improvements.

These observations are by no means intended to be exhaustive. But they do give us a good point of the departure to re-evaluate the process and make the necessary improvements. It is, no doubt, an on-going process.

\section{Final Remarks}

In this paper we have presented the experience of three different linguistic projects, where the role of the native speaker went beyond that of mere informant to become an agent in the process of uncovering knowledge. Though an outsider linguist was present, the whole process took the shape of a co-learning process where each member learned from the others and from the process itself. The goal of such an approach was to create a more equal-to-equal relationship between the different participants of the linguistic research in the context of an endangered language. Within a background framework of participatory action research, a concomitant goal was that of effecting change in a situation of disadvantage, that is, to empower the community. Have these goals been attained? Have these actions effected any substantial change? Is the community more empowered as a result of such a process?

These are difficult questions to answer right now. Obviously, these projects did attain the specific goals that were set up (see $\S 1$ ): (i) the community has become more involved in the linguistic activities, by having some of its members actively participate in them and by having town meetings ('validaciones') where the materials were presented (i.e., returned to the community) and evaluated by the community itself; (ii) presumably, a more equal-to-equal relationship was established, since the local members were able to make their own decisions in the process, though the role of the outsider linguist was still distinct; and (iii) there was transfer of "linguistic technology" in the sense that a group of native linguists is emerging.

Obviously, there has been change, but is the community at large more empowered? The challenge now is to integrate those changes more fully into the community itself, without provoking a loss of cultural identity. Though most of the work in these projects came out of the communities, it is still difficult to be self-sufficient, since most do not have electricity or are difficult to access. 
Moreover, some of the members of the teams have been offered jobs at institutions working out of town, so in a way there has been a sort of brain drain.

It cannot be stressed enough that this is an ongoing process, where all of us are responsible agents and where continuing self-evaluation is a tool of utmost importance to keep at the task of working towards our goals.

\section{References}

Bach, E. 1995. Endangered languages and the linguist. In Ik-Hwan Lee (ed.) Linguistics in the Morning Calm 3: Selected Papers from SICOL 1992, 31-43. Seoul: Seould Hanshin Publishing Company.

Benedicto, E. \& K. Hale. 2001. Mayangna, a Sumu language: Its variants and its status within Misumalpan. In Benedicto, E. (ed.) The UMass Indigenous Languages Volume. UMOP [University of Massachusetts Occasional Papers] 20. University of Massachusetts, Amherst.

Benedicto, E., M. McLean, M.Dolores, A.Jacobo, C.Poveda \& E.Salomón. 1999. Mayangna Yayal Sangninaka Yulni / Mayangna Wawana Yalalahwa Yuln. ('Mayangna Women's Life Stories'). Managua, Nicaragua: OED and Terra Nuova.

Breve Vocabulario Twahka. 1996. CIDCA, MIT, UMass.

Christie, P., D. Bradford, R. Garth, B.González, M.Hosteler, O.Morales, R.Rigby, B.Simmons, E. Tinkam, G.Vega, R.Vermooy, \& N.White. 2000. Taking Care Of What We Have. Participatory Natural Resource Management On The Caribbean Coast Of Nicaragua. Managua and Ottawa: Centro de Investigación y Desarrollo de la Costa Atalántica (CIDCA) and International Development Research Centre (IDRC).

Craig, Colette, and Ken Hale 1992. A possible Macro-Chibchan etymon. Anthropological Linguistics 34:173-201.

Deloria, V.Jr. 1969. Custer Died For Your Sins: An Indian Mannifesto. New York: McMillan.

Hale, K. 1996. UG and the roots of linguistic diversity. In J.D. Bobaljik, R. Pensalfini \& L.Storto (eds.) Papers on Language Endangerment and the Maintenance of Linguistic Diversity, MITWPL 28:137-161. 
Hale, K., M. Krauss, L. Watahomigie, A. Yamamoto, C. Craig, L. Masayesva Jeanne \& N. England. 1992. Endangered languages. Language 68:1-42.

Mayangna Dictionary. in prep. CIDCA.

McLean, Melba. 1996. Diccionario Panamahka. Sumo-Español-Sumo. Managua, Nicaragua: CIDCA.

Norwood, Susan. 1988, 1997. Gramática de la Lengua Sumu. Managua, Nicaragua: CIDCA.

Elena Benedicto

Linguistics Program

Heavilon Hall 307B

Purdue University

West Lafayette, IN 47907

benedict@omni.cc.purdue.edu

Modesta Dolores

c/o IPILC - URACCAN

Radio Rosita

Rosita, RAAN (Nicaragua)

ipilc.uraccan@ifxnw.com.ni

Melba McLean

CIDCA

del campo de beisbol, 50v. al mar

Bilwi, RAAN (Nicaragua)

estermelmclean@yahoo.com 